\title{
Water, Sanitation and Rural Livelihoods Nexus: An exploratory Study of Wogu in the Upper West Region of Ghana
}

\author{
Nicholas Fielmua \\ (Corresponding Author) \\ University for Development Studies, Department of Planning, Wa Campus. Ghana \\ Email: nfielmua@uds.edu.gh \\ Mamudu A. Akudugu \\ University for Development Studies, IIRaCS, Tamale, Ghana

\section{Gordon Dugle} \\ University for Development Studies, SBL, Wa Campus, Ghana \\ DOI//http://dx.doi.org/10.4314/gjds.v16i2.10
}

\begin{abstract}
Improving access to safe water, adequate sanitation and proper hygiene are on the frontline of efforts to combat related diseases and their accompanying effects. Using a household survey, focus group discussion and key informant interviews, the authors explored how rural livelihoods could be improved through water and sanitation interventions. The study revealed a complex web of configuration between water and sanitation interventions and rural livelihoods. The study found that the provision of water and sanitation infrastructure does not guarantee reductions in related diseases and improvements in livelihoods. Although rural dwellers are aware of the consequences of poor sanitary and hygiene conditions, related diseases and the implications on livelihoods, their persistent demonstration of poor sanitary and hygiene behaviours attributable to intertwined historical and socio-economic factors, adversely affect interventions. Thus, the organisation and management of water and sanitation interventions, require an integrated attention to behaviour change mechanisms.
\end{abstract}

Keywords: Water-related Diseases, Access to Water, Hygiene, Livelihoods, Sanitation 


\section{INTRODUCTION}

Access to potable water and improved sanitation services is a topical issue in the global community development agenda. This assertion is consistent with evidence in the empirical literature that improved access to safe drinking water and sanitation is crucial to tackle health problems and promoting livelihoods in general, especially in rural communities (Dangour, Watson, Cumming, Boisson, Che, Velleman, Cavill, Allen \& Uauy, 2013). According to Zhang (2012: 122), in rural China, village level access to water resulted in a reduction in incidences of "illness among adults by $11 \%$, and an increase in weight-for-height by $0.835 \mathrm{~kg} / \mathrm{m}$ ". Thus, improved water and sanitary situations minimise poor growth in children caused by infectious diseases that expose them to illness and death (Dangour et al., 2013). This holds true because Zhang established that as a result of a water programme, "children's weight-for-height and height itself both rose by $0.446 \mathrm{~kg} / \mathrm{m}$ and $0.962 \mathrm{~cm}$ respectively" (Zhang, 2012: 122). Globally, many other studies have also shown that improvements in access to quality water and sanitation, and proper hygiene practices contribute to the improvement of livelihoods through a reduction of related diseases (Cheng, Schuster-Wallace, Watt, Newbold \& Mente, 2012; Dangour et al., 2013). Using data from 193 countries, Cheng et al. (2012) established that there is also a strong relationship between access to water and sanitation, and a reduction in maternal and child mortality. This implies that achieving the Sustainable Development Goal 3 (ensuring healthy lives and promoting well-being for all at all ages) requires serious intervention in improving safe water and sanitation, hygiene infrastructure and practices.

In Ghana, a specific intervention to provide safe water through the drilling of 159 boreholes and wells across selected villages in the Nanumba District where guinea worm was endemic, resulted in a $77 \%$ reduction in the incidence of the disease from 14,000 cases in 1989 to 3,24l in 1990 (WHO, 1992). Besides the direct health benefits, there are economic benefits of improved access to safe water and sanitation services. It is established that after achieving the erstwhile Millennium Development Goal (MDG) target for water, "63\% of the benefits are attributed to convenience timesavings, $28 \%$ to productivity gains, and $9 \%$ to health care cost savings" (Hutton, Haller, \& Bartram, 2007a: viii). The economic benefits of sanitation, on the other hand, are more heavily dominated by convenience time-savings, at " $90 \%$ of the total economic benefit, followed by $8 \%$ to productivity gains, and $2 \%$ to health care cost savings" (Hutton et al., 2007a:23). These positive gains are central to livelihoods and community development.

Notwithstanding the numerous benefits associated with access to quality water and improved sanitation facilities, water and sanitation related diseases remain a 
growing human tragedy, killing many people. Over five million people die annually from such diseases, which is decuples the number of people exterminated in armed conflicts (Curry, 2010; United Nations, 2003). Water-related diseases remain a main source of morbidity and mortality in the world and excessively affect the poorer populace in any society (WHO/UNICEF, 2014). Based on these griming statistics, it is observed that the supply of water and sanitation facilities is a leading intervention that can have significant influence on livelihood in general and public health in particular (Usman, Gerber \& von Braun, 2018).

Despite years of concerted efforts to improve the provision of water and sanitation facilities with the objective of eradicating related diseases and consequently improving livelihoods, these interventions have generally not achieved the desired results in Ghana. In the Upper West Region in particular, rural livelihood statistics are still poor and poverty remains highest in the country (70.9\%) (Ghana Statistical Service, 2018). The water sector has been viewed narrowly, without drawing critical linkages between water and other dimensions of community development, such as livelihood, community level social capital and the social and cultural values that they attach to water (Saleth \& Dinar, 2004; Schouten \& Moriarty, 2003). This paper therefore explores how access to safe water and improved sanitation services could lead to improved rural livelihoods. Specifically, it analyses the water and sanitation practices of the people, household knowledge on major disease causation in Wogu, a farming community in the Upper West Region of Ghana, and conceptualises the link between safe water, sanitation and rural livelihoods, drawing implications for community development.

\section{Link between Water, Sanitation, and Community Development}

The current approach to water and sanitation delivery in rural areas in many sub-Saharan African countries, especially in Ghana, is based on community management. Doe and Khan (2004:362) explained community management as a "bottom-up development approach in which the members of the community have a say in their own development and assume control - managerial, operation and administrative responsibility - of their water facilities". They see the 'control' dimension as a product of community empowerment, which is a central to community development. This suggests that in addition to the water sector, community management addresses other dimensions of community development. This makes it necessary to comprehend community development and empirically explore how water, sanitation and rural livelihood nexus play into it.

Community development is defined as "a process designed to create conditions of economic and social progress for the whole community with its active participation" 
(United Nations in Gilchrist \& Taylor, 2016:1). Social and economic progression involves provision of infrastructure to deliver water and sanitation services. For economic progression, livelihood enhancement is a core component of community development and a determinant of access to water and sanitation services (Gilchrist \& Taylor, 2016). Economic/livelihood enhancement, health and wellbeing are at the forefront of community development and as such policies geared towards livelihood enhancement will contribute to a comprehensive community development (Hutton, Haller, \& Bartram, 2007b). It has been established that the economic status of a household is a key determinant of access to water and sanitation services: better-off households can purchase quality water and sanitation services (Adams, Boateng \& Amoyaw, 2016). On the other hand, limited access to quality water and sanitation services often lead to inefficient production and health-related costs (Hutton et al., $2007 \mathrm{~b}$ ). These findings have significant implications for community development, especially in rural areas where livelihoods depend on rain-fed agriculture.

The desire to increase water and sanitation services for rural households, especially the poor, is a priority and community development approach, which requires community members to be able to influence decisions that affect their lives, is used to deliver interventions (Clarke, Feeny \& Donnelly, 2014). Community development is a core component of Ghana's water and sanitation sector development agenda with particular focus on a decentralised (bottom-up) approach to delivering water and sanitation services in rural areas. Under the 'community rights' agenda, there is an increasing demand on communities to take up responsibility in the management of their assets and services (Gilchrist \& Taylor, 2016) including water and sanitation services. This approach entrusts management decision making to the community and thus, effective engagement with all members of the community is significant. The underlying principle of water and sanitation services delivery in rural communities, especially in Ghana is equity and empowerment (Gilchrist \& Taylor, 2016). Equity takes into account the diverse values of participants with the aim of eliminating discrimination while empowerment emphasises collective leadership - community members contributing to decision making about issues concerning them.

In Ghana, the institutional arrangements for water services delivery in rural areas promote community-based management, which is a practice that enjoins beneficiary communities to take full responsibility and make decisions about how the water facilities should be managed, including tariff setting, and the people to employ to take care of operation and maintenance activities (CWSA, 2011). Legal ownership of the water facilities is vested in the District Assemblies, while the right of access to the facilities is vested in the communities, which are also responsible 
for their operation and maintenance. Community level management structures, in consultation with the community, propose tariffs for deliberation and approval by the District Assembly (CWSA, 2011, 2014). Water services delivery in small towns and rural communities in Ghana is monitored to ensure transparency and equity using the operations manual. As such, communities can demand accountability from the District Assembly, by writing to the Complaints Committee of the Assembly through their Assembly members, in cases of any mistrust in the process of water services delivery (CWSA, 2014).

\section{METHODOLOGY AND THE RESEARCH SETTINGS}

\section{Research Design, Data Collection and Analysis}

The mixed methods research design was employed to investigate the intrinsic links among water, sanitation and livelihoods. The main reason for employing the mixed methods design is to ensure that the findings are practically relevant to policy and practice in the water, sanitation and rural livelihoods sectors. Consistent with mixed methods research epistemology, qualitative and quantitative data collection tools, including focus group discussions (FGDs), key informant interviews, physical observation and a household survey were used. Although in practice women in rural communities are in charge of water and sanitation management in their households (Giné \& Pérez-Foguet, 2008), the role of their spouses in this regard cannot be underestimated. Thus, the study focused on household heads and/or their spouses as the research participants. In all, 30 households were randomly sampled and surveyed, and the respondents comprised 24 women (80\%) and six men (20\%). The households were randomly selected for survey because of the authors reasonably believed that the participating households are homogenous in their water and sanitation practices as well as livelihood strategies.

The key variables examined within the context of livelihoods included household access to water; basic hygiene practices and access to toilet facilities; the mode of water collection, transportation and storage; mode of determining water purity; and household knowledge of disease causation. Physical observations of household surroundings, water collection and storage practices, sanitation facilities and mode of managing children faeces were conducted. There was also a FGD with members of the community's Water and Sanitation Committee (WATSAN), which is responsible for the daily management of water and sanitation facilities and general maintenance of hygiene in the community. Key informant interviews were conducted with the Assemblyperson and two other opinion leaders. The Assemblyperson is a non-partisan politician who is elected by universal adult 
suffrage, from a local government electoral area within the District to serve a fouryear term subject to re-election. These people were selected as key informants because of their knowledge of development issues in the community, especially on livelihoods, water and sanitation.

The data collection tools were designed with flexibility in mind so as to allow easy capturing of the diverse lived experiences as well as water and sanitation practices of the research participants. This made the data grounded in the respondents' perspectives on livelihoods, water and sanitation practices used for general community development (Clarke et al., 2014). The use of multiple sources of data was for purposes of triangulation and cross validation of the research findings on water, sanitation, and rural livelihood issues in the community. The data from key informant interviews and FDGs were recorded using digital audio recorders, subject to the consent of the participants, transcribed and analysed according to emerging themes. The discussion and interviews were conducted in the local language (Dagaare). The key questions asked during the interviews and discussion covered the key variables as stated earlier.

\section{Research Setting}

The study was conducted in Wogu, a rural community in the Daffiama-Bussie-Issah District in the Upper West Region of Ghana. Wogu has two major sections, namely; Wogu-Kpong and Ligeri. According to the Ghana Statistical Service (2013), Wogu has a total population of 2,752, comprising approximately equal number of males (50.1\%) and females (49.9\%). The community has 417 houses, consisting of 442 households, giving an average of 1.1 households in a house. The average household size of the community is 6.2, as compared to the district average of 6.4. The community has 13 boreholes fitted with hand pumps, out of which 11 are functioning while two are completely broken down. This gives a functional borehole ratio of 250 persons per borehole and this is within the standard ratio of a maximum of 300 persons per borehole as set by the Community Water and Sanitation Agency of Ghana. In terms of spatial distribution of the facilities, six boreholes are located in Ligeri and seven in Wogu-Kpong. The two non-functional boreholes are located in Ligeri. According to the WATSAN committee, only two boreholes out of the seven in Wogu-Kpong produce water throughout the year. During the dry season the water yield is so poor that the remaining five boreholes become non-productive. Moreover, excessive use of the boreholes, especially in the dry season, leads to frequent breakdowns. 


\section{RESULTS AND DISCUSSION}

\section{Sources of Drinking Water across Seasons}

The sources of drinking water in the community vary across seasons because seasonal variations affect potable water supply in purely rural environments like the one studied. It was found that households rely on boreholes, streams, rivers and rainwater for drinking. Whereas almost all the households surveyed use borehole water as their main source of drinking water in the dry season, some rely on onfarm water sources such as streams, rivers and ponds for drinking water while on the farms in rainy season. These water sources are categorised as unwholesome by the Ghana Water Company Limited and the Community Water Sanitation Agency. According to the respondents, long distances, an average return journey of $12 \mathrm{~km}$ to the farms account for use of these unwholesome sources of drinking water on the farm. For those who use water from boreholes with hand pumps on the farm, two main categories were identified. The first category is households that have motorbikes and 2oliter-containers (locally referred to as "jerrycans" or "Kuffour" gallons). This is usually in addition to smaller quantities that the women usually carry to the farms. The second category constitutes households whose farms are located near other communities with boreholes with hand pumps. In this case, they seek permission from such communities to use their water facilities when they are on the farm. Households that do not have farms close to either their communities or other communities with boreholes are obliged to rely on streams and ponds. Table 1 shows the sources of drinking water in Wogu.

Table 1: Sources of drinking water

\begin{tabular}{|l|l|l|l|}
\hline \multirow{2}{*}{ Source } & \multicolumn{2}{l|}{ At Home } & On the farm \\
\cline { 2 - 4 } & Dry season & Rainy season & \\
\hline Borehole with hand pump & $100 \%$ & $88.3 \%$ & $30 \%$ \\
\hline Rain harvesting & - & $11.7 \%$ & $5.3 \%$ \\
\hline Stream & - & - & $18.3 \%$ \\
\hline Pond & - & - & $23.4 \%$ \\
\hline Total & 100 & 100 & 100 \\
\hline
\end{tabular}

Source: Field survey (2017).

The use of rainwater as source of drinking water in the rainy season applies to domestic use. While rainwater can be considered pure, the mode of collection can degrade its quality. The main containers used to harvest rainwater are basins and plastic barrels. The main reason for using rainwater is to save time and energy 
in traveling to boreholes fitted with hand pumps. This means that rain water harvesting is considered more convenient in relation to fetching water from boreholes with hand-pumps. About $60 \%$ of the respondents were of the view that, rain water harvesting has reduced the time wasted in drawing water (traveling to riverside or queuing at the boreholes), and this supports the findings of Dangour et al. (2013).

In addition to the above sources of water, the discussion with the WATSAN committee revealed that during traditional rites such as funerals, the community members dig wells to enable the women draw water for the rites. The wells, which are termed here as "traditional wells" are dug using communal labor. It is mandatory for all households to contribute labour in digging the wells and households that fail to participate are fined. Accordingly, water from the boreholes cannot be used for rites. The hand-dug wells often dry up within a month after the traditional rites and as such these are not reliable sources of water. The use of traditional hand-dug wells fosters social cohesion, which is necessary for community development. It has been argued that people who have trust and confidence in their collective or cultural identities are likely to be oriented towards community development. Similarly, community development principles can facilitate organisation and management of water, sanitation and hygiene services by empowering community members in decision making and promoting inclusivity and accountability (Gilchrist \& Taylor, 2016). This is particularly relevant to the water sector of Ghana where community ownership and management of water infrastructure is being strongly promoted. Therefore, there is a symbiotic relationship between water and sanitation, livelihoods and community development.

\section{Water Treatment Practices}

Based on the identified sources of drinking water, the respondents were asked whether they treated the water, especially on the farm, before drinking. The results show that majority (80\%) of the people do not treat their water in any form before drinking. With a higher direct proportion between users of unsafe water on the farm (70\%) and people who do not treat the water before drinking (80\%), the incidence of water and sanitation-related diseases is likely to be high in the rainy season, resulting in ill-health and poor livelihoods. In other words, as farmers contract water and sanitation related diseases in the rainy season, they are unable to work on their farms and this leads to poor harvest that translates into poor livelihood outcomes such as low incomes and food insecurity. For those who treat water on the farm, the main methods of water treatment are sieving and boiling. The FGD with the WATSAN Committee confirmed by some the household interviews, showed that hitherto water was boiled in the evening on the farm and left overnight (stored in 
farms huts) to cool for usage on the following day. This practice has stopped due to safety concerns and the current practice is that water is boiled on the day of usage.

\section{Hygiene and Sanitation Practices}

The most viable indicator of good sanitation is the presence and usage of improved toilet facilities. Like many rural communities in Ghana, Wogu has very few toilet facilities. According to a key informant, there were initiatives for households to acquire toilet facilities (pit latrines) but it was not successful due to three main factors: the onset of the rainy season; the presence of a public toilet; and reluctance of some households to acquire their own toilet facilities. Wogu-Kpong and Ligeri have a public toilet each but a physical observation of these facilities showed that they are in deplorable conditions. The FGD revealed that only one household in Wogu-Kpong and relatively higher number of households in Ligeri have pit latrines. A key informant indicated that none of the toilets (public and households) have ever been siphoned. Only $5 \%$ of households have household latrines. In all, $25 \%$ of the households surveyed regularly use the public toilet facilities while the remaining $70 \%$ defecate openly in nearby bushes. The obvious result of the high proportion of open-field defecation is contamination of water sources as heavy rains wash the human excreta into streams, rivers and other open water bodies. In consequence, this leads to poor livelihood outcomes.

Another sanitation issue is the disposal of excreta of children. It has long been established that in households where children's excreta are properly disposed in toilet facilities, they are less likely to have diarrheal diseases (Curtis, Cairncross, \& Yonli, 200o; Strina, Cairncross, Barreto, Larrea, \& Prado, 2003). Due to the absence of household toilet facilities, the management of human waste, especially of children, is poor as indicated by all the research participants. In houses where potties are used, the lack of household toilet facilities compels mothers to dispose of children's excreta in refuse dumps locally referred to as "tampuor" and these are located within the immediate surroundings of the house. The study revealed that about $92 \%$ of households throw the excreta of children in the bush behind their houses, while about three percent bury (cover with soil) the excreta of children. Only five percent, representing those with household toilet disposed the excreta of children into their facilities. Overall, the absence of household toilet facilities in many homes has affected the positive relation between improved excreta disposal and potential reduction in diarrheal diseases, with consequences on livelihood outcomes.

With low access to toilet facilities, the study explored the practice of hand washing, especially with soap after defecation and management of children's excreta as this 
has been found to be important in reducing diarrheal diseases (Dangour et al., 2013; Kendie, 2002) In terms of hand washing, majority (62\%) of the respondents indicated that household members washed their hands after defecation and/or managing children's excreta, although throughout the household survey we never chanced/spotted washing hand with soap. Out of the $62 \%$ who washed their hands, only $13 \%$ did so with soap while $49 \%$ washed without soap. Hand washing with soap was limited to instances when members are at home. When household members are on the farm hand washing with soap after toilet is not practiced because it is not practically possible to carry soap on daily basis to farm for hand washing. Many households literally understood 'hand washing' to simply mean using water to wash hands, instead of looking at it in terms of using soap or other detergents. When asked about hand washing with soap, a household respondent expressed concerns about affordability as captured in the following excerpts:

... We know that hand washing with soap is good. But we get soap mostly on market days at a relatively high price. ... That soap is not even enough for our clothing let alone washing hands with it after each toilet visit. ... If the whole household of 11 members will have to wash with soap after each toilet visit, we cannot bear the cost (Household survey, 10 September 2017).

While households may know the significance of hand washing with soap, the ability to provide soap and inadequate knowledge of locally available detergents such as ash can constrain the efforts of promoting the practice. Certainly, the income levels of households can influence the incidence of water and sanitation related behaviours in those households as established by Bartlett (2003) and Montgomery and Elimelech (2007).

\section{Water Collection, Transport and Storage}

It has been established that better water source alone cannot accomplish full health benefits (Checkley, Gilman, Black, Epstein, Cabrera, Sterling, \& Moulton, 2004). Since the water points are usually some distance away from the house, it has to be transported home. The vessels used in the community include basins, buckets and others. In $73 \%$ of the households, women were the main drawers of water while $27 \%$ of the respondents indicated that children were the most frequent drawers of water for domestic use. This is consistent with the extant literature that drawing water for domestic use in many rural communities is largely the responsibility of women and children (Giné \& Pérez-Foguet, 2008; Gleick, 2002). Men in Wogu are not involved in collection of water for domestic use. In view of the tendency for children to be 
careless during collection, transportation and storage of water, relying on them for the drawing of domestic water cannot guarantee safety.

During transportation, the water tends to splash away or on the person carrying it. In that respect, respondents were asked to explain how they controlled the splashing of water during transportation. The results showed that most women (40\%) dipped polythene into the water, whereas $35 \%$ use containers such as calabash or plastic bowls, which they capsise in the basin. Interestingly, some respondents indicated that they used to dip leaves into the water to prevent splashing but this practice has since stopped because of the risk of contamination. This confirms earlier studies which revealed that in the Upper Region of Ghana, about $11 \%$ and $4 \%$ of women interviewed used leaves (taken along roadside) and polythene respectively to control water splashing (Kendie, 2002). The use of leaves and polythene, mostly dirty and/or infested, naturally reduces the quality of water and increases the risk of water and sanitation - related disease infection. About $25 \%$ of the respondents put nothing into the water but rather stop for the splashes to subside before they continue to move, but people who live very close to the water point practice this.

It was observed that drinking water is stored in either covered or open earthen pots or barrels. Expectedly, the use of uncovered storage vessels can result in water contamination. Therefore, despite the presence of and access to potable water, the mode of collection, transportation and storage can contaminate the water and result in its related diseases. This finding collaborates that of Kendie (2002) that there is a relationship between the type of storage container and the incidence of diarrheal diseases. He concluded that storing water in long necked earthen pots helped to reduce diarrheal diseases while buckets, which are uncovered containers, rather increased the incidence of diarrheal diseases. This implies that the quality of water often changes at the point of use. Studies have shown that a common cause of water contamination in Third World countries is scooping it up from uncovered vessels with unwashed cups and/or hands (Rufener, Mäusezahl, Mosler, \& Weingartner, 2010; Wright, Gundry, \& Conroy, 2004). Water contamination is also influenced by lack of basic sanitation, use of different pots for carrying and storing water, the way water was drawn at the source, and use of earthenware pots as water containers (Mohamed, Clasen, Njee, Malebo, Mbuligwe \& Brown, 2016). This is probably why in most communities in developing countries the level of water - related diseases did not decrease despite the provision of potable water (Wright et al., 2004).

\section{Determining the Purity of Water}

Household knowledge on the purity of water is important in reducing related diseases. The respondents were asked to explain how they determine the purity of 
water. With multiple methods of determining water purity, $80 \%$ of the respondents use the colour of the water to determine its purity. According to them, water must look transparent before it is branded pure. Those who use the smell of water to determine its purity constitute $30 \%$ whereas about $2 \%$ mentioned technical test, usually carried out by experts, to determine its purity. For these respondents, when a technical test is conducted (mostly immediately after installation of the pump) and the results show that the water is pure, they rely on such results. Some $6 \%$ consider the thickness of the water (i.e. thick water is not pure) as well as the presence or absence of dirty particles inside the water to determine its purity. Clearly, respondents' methods of determining water purity raise concerns that challenge key players of water, sanitation and hygiene (WASH) need to intensify continuous water testing education to help people determine the purity of water at the point of consumption and not only at the source. This will help prevent people from being infected with water and sanitation related diseases through the consumption of contaminated water.

\section{Common Diseases and Awareness of the Causes}

The respondents were required to list the common disease complaints within their households in ascending order of severity. Figure 1 gives the pattern as identified by the respondents.

\section{Figure 1: Common Disease Complaints from the Household}

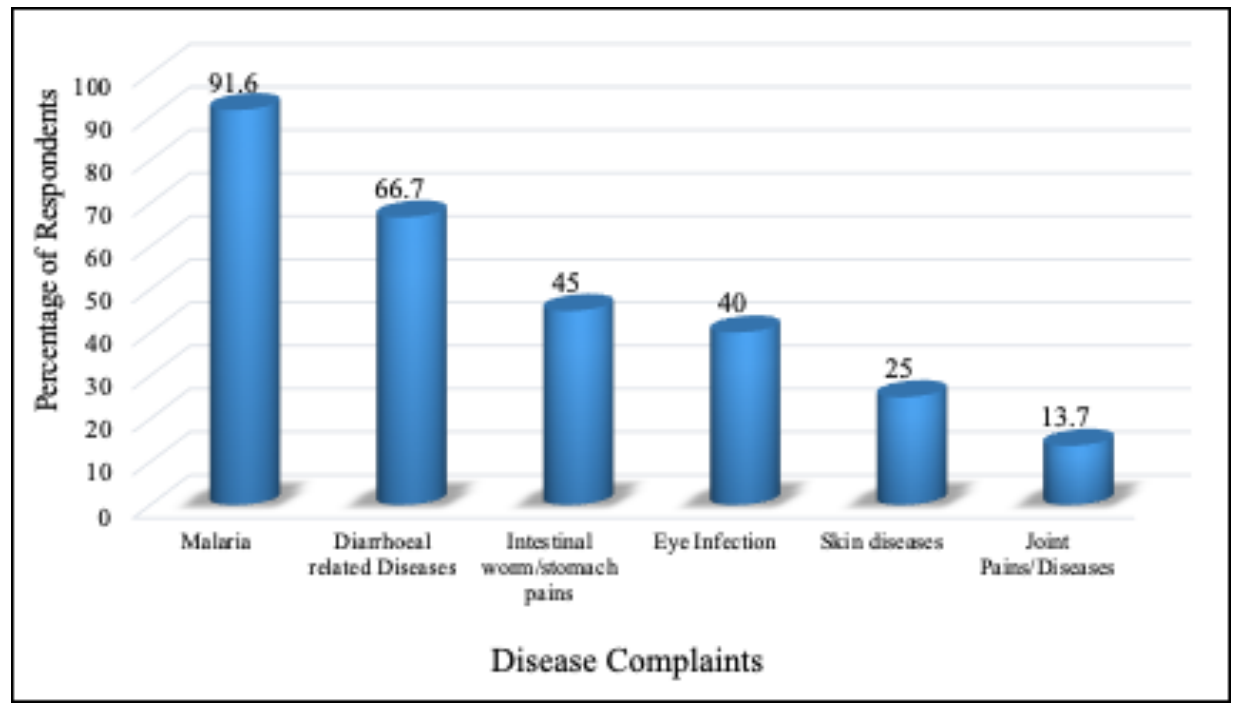

Source: Field survey (2017) 
Respondents were also asked to explain the causes of the various diseases mentioned. About $20 \%$ of the respondents could not identify a single cause of the diseases mentioned. Out of the about $92 \%$ who complained of malaria, about $65 \%$ said mosquitoes bite were the mode of transmission while the rest attribute it to weather changes and negligence which exposes household members to the disease. In terms of diarrheal diseases, about $40 \%$ of those who complained identified eating contaminated food and drinking infested water as the cause, whereas $3 \%$ attributed it to eating fatty foods. As to where households seek treatment when they contract the above diseases, about $67 \%$ seek treatment at health facilities such as Community-Based Health Planning and Services (CHPS) compound in Wogu, and the remaining 33\% resort to self-medication. Self-medication includes the use of herbs and purchase of drugs from chemical stores without professional prescription. Empirically, it has been established that when children drink quality water, the chances of them suffering from diarrheal diseases is minimal (Graf, Meierhofer, Wegelin \& Mosler, 2008). However, some households' knowledge on children suffering from diarrheal diseases differ. About 3\% of the households viewed diarrheal diseases among children as a symptom of the child's human system reacting to breast milk and as such ready to be weaned. This implies that diarrheal diseases among breast-feeding children are seen as normal indicators of readiness for weaning to take place. Similarly, in Karachi (Pakistan), childhood diarrhoea is considered a normal condition, related to teething (Bartlett, 2003). This understanding of diarrheal diseases can be dangerous to the health of the child because not all diarrheal cases among children are associated with teething or signs of readiness for weaning.

In terms of eye infection, $96 \%$ of the respondents who complained of it identified wind as the cause, whereas others (4\%) viewed eye infection as "a year with its diseases". They thus cited instances where diarrheal diseases and guinea worm were common in some years and, as such, this is a year of eye infection. This means that there is some superstition among rural people particularly in the study area that each disease has a specific year of occurrence, and this has the tendency to make community members take outbreaks for granted as "passing by" conditions. In addition, out of the $45 \%$ who complained of intestinal worms/stomach pains, about $20 \%$ identified eating of contaminated food and drinking of infested water as the cause. Although guinea worm has been eradicated (Ghana Health Service, 2012) many respondents are aware that anyone who drinks or gets in contact with contaminated water could contract it. Respondents also identified skin diseases to be caused by wind and insects bites. Further, those who complained of joint pains/ disease attributed it to accidents and/or old age. These findings call for intense 
community health education to enhance awareness on the causes, prevention as well as the treatment of the aforementioned diseases.

\section{Safe Water, Improved Sanitation and Livelihoods Linkage}

The ripple effects of limited access to quality water and sanitation services have been established in the literature. Dangour and colleagues identified the pathways (direct and indirect) that link inadequate access to water and health status of the populace. The direct pathways relate to poor water quality that result in diarrheal related diseases whereas the indirect pathways relate to the time taken to access water and its effects on individual productivity in other sectors and household income in particular and livelihoods in general (Dangour et al., 2013). This implies that, when people live in poor conditions with limited access to safe water and sanitary facilities, they are at risk of water and sanitation-related diseases. Overall, the diseases are not ends in themselves but rather proceed to manifest in other socio-economic aspects of the lives of those affected. While the immediate cost of building fresh water supply and sanitation facilities is high, the medium to longterm cost of not doing so can be staggering. For instance, in Karachi, Pakistan, a study found that poor people without access to any sanitation spent six times more on medical care than people who have access to sanitation (WHO, 2002). According to the United Nations (2003), water and sanitation-related diseases cost Africa more than $\$ 12$ million annually and slow economic growth in the continent by $1.3 \%$ a year.

Regarding deaths resulting from these diseases, about 90\% of the annual global rates of deaths from malaria occur in sub-Saharan Africa (SSA), leading to loss of productive labour (United Nations, 2003). The situation is not different in Ghana. During 1991, Ghana News Agency reported that the price of yam in Northern Ghana became depressed because of "yam glut" resulting from stepped up production attributed to the relative absence of dracunculiasis (WHO, 1992:8). There is therefore a link between unsafe water and sanitation and poverty, because water and sanitation related diseases lead to loss of working hours and draining of family scarce resources (Gleick, 2002). It is therefore not surprising that studies in Burkina Faso have shown that the location of water facilities is more important to customers than health, income and maternal education (Bartlett, 2003). As women and children are the main water drawers and during periods of scarcity, the time spent in search of water makes women to forgo economic hours (Montgomery \& Elimelech, 2007). Figure 2 presents the link between lack of adequate water sources and loss of productive time that leads to low productivity and household income, and consequently poor livelihoods. 


\section{Figure 2: Safe water, sanitation and livelihoods link}

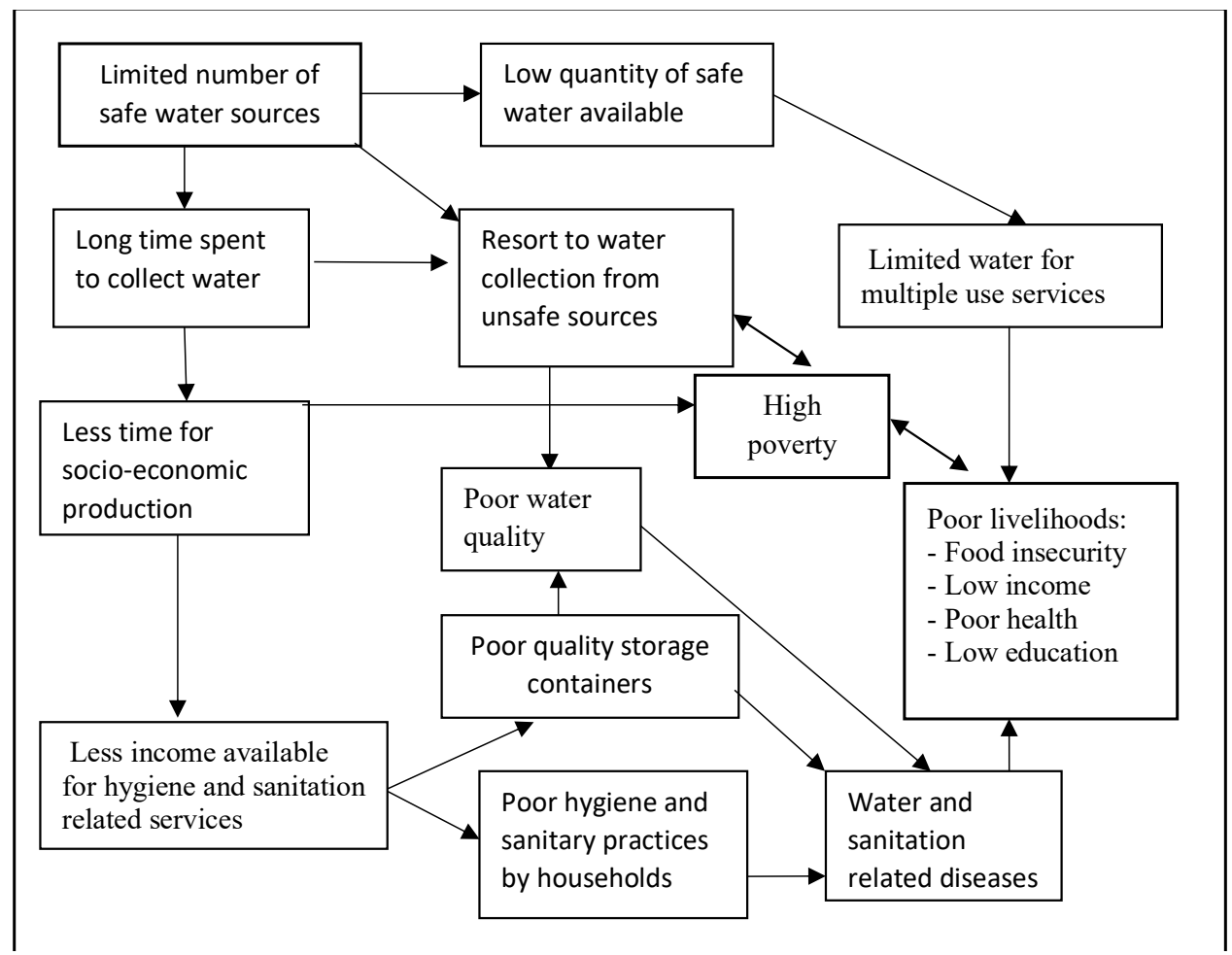

Source: Authors' Construct, 2017.

The quantity and quality of water remain critical issues of concern worldwide because limited quantity of safe water and the risk of degrading water quality affect social and economic aspects of society. The major concern is that many community development goals in terms of poverty reduction, eradication of maternal and child mortality are related to water and sanitation (Cooley, Ajami, Ha, Srinivasan, Morrison, Donnelly \& Christian-Smith, 2014; Jasper, Le \& Bartram, 2012). The death of one productive person due to water-related diseases could affect production of an entire household. Poverty, sometimes measured in terms of income of the household, manifests itself in people's inability to provide themselves with improved sanitation and ensure good hygiene practices. Again, water related diseases result in debilities, financial cost and health cost in the form of loss of lives. These adversely affect economic activities, finally resulting in poverty. Additionally, for equal access to education, improve access to water and sanitation can increase pupil attendance in school. The absence of water and sanitation affects school attendance of children (Gleick, 2002; Jasper et al., 2012). Freeman, Greene, Dreibelbis, Saboori, Muga, Brumback and Rheingans (2012) established 
that improvement in water supply in schools reduced absenteeism among pupils. Furthermore, access to improved sanitation is a key component of privacy, safety and menstrual management among school girls (Freeman et al., 2012).

The time saved in collecting water can be used in income generating activities and education and this contributes to women empowerment and gender equality. It has also been established that diarrheal and lower respiratory infections are among the dominant killers of children and improved access to water and sanitation could reduce these diseases (Opryszko, Guo, MacDonald, MacDonald, Kiihl \& Schwab, 2013; WHO, 2002). According to Fewtrell, Prüss-Üstün, Bos, Gore, and Bartram (2007), the risk associated with poor access to quality water and sanitation is a major contributor to gastro-intestinal infection, which results in less absorption of nutrients. This causes malnutrition in children (Ejemot, Ehiri, Meremikwu, \& Critchley, 2008; Fewtrell et al., 2007), which is an indicator of poor health and livelihoods status generally. Moreover, lack of water limits the practice of proper hygiene (Montgomery \& Elimelech, 2007). In a Peruvian peri-urban area, Checkley et al. (2004) established that children from households with small storage containers had $28 \%$ more diarrheal episodes than did children from households with large containers. Although the size of storage containers may be linked to household size, which the study did not specify, the size could also be associated with cost, that is, larger containers, given the same quality, can be associated with higher cost.

With increasing scarcity of water, there is a conscious effort to structure multiple uses of the existing water sources, and this has been extensively discussed in the empirical literature (Van Houweling, Hall, Sakho Diop, Davis, \& Seiss, 2012; Van Koppen, Moriarty \& Boelee, 2006). Consequently, as various sectors compete for water, its scarcity is projected to become a more important determinant of food insecurity (Hanjra \& Qureshi, 2010). Although various explanations have been given to food security (Pinstrup-Andersen, 2009), all converge at the point that there should be sufficient food with high nutritional value (quality of food) and at affordable price. These quantity and quality aspects imply that food insecurity can have major impact on the health and livelihoods of the people and general community development.

In summary, there is an explicit complex nexus between access to safe water, improved sanitation practices and rural livelihoods and these collectively shape community development. Thus, limited number of safe water sources lead to three main outcomes: (i) limited water available for multiple uses and this negatively affects livelihoods; (ii) households have to spend so much time looking for water and this implies less time is left for carrying out productive activities; and (iii) makes households to resort to using water from unsafe sources and this results 
in related diseases which negatively affect the welfare of households. Moreover, inadequate access to safe sanitation leads to related diseases, which often have to be treated with limited family resources. In effect, households with poor access to safe water and improved sanitation practices experience poor livelihood conditions as these affect their food security, health, income, education and natural resource use situations.

\section{CONCLUSION}

This paper presents the links between water, sanitation and rural livelihoods and how such links feed into community development. Water and sanitation-related diseases still remain a key setback to community and livelihoods development interventions, especially in rural areas. In reducing the toll of these diseases, many organisations have committed themselves to providing water and sanitation facilities. However, the argument that water and sanitation-related diseases can be reduced drastically through the supply of water and sanitation facilities is not wholly tenable in rural areas. Thus, the provision of basic sanitation and reliable supply of safe water is necessary but not sufficient condition to guarantee reductions in their related diseases and improvements in health and livelihoods. This is because there is a configuration of many factors (water collection, transportation and storage systems, poverty, attitude/hygiene behaviour) surrounding water and sanitationrelated diseases. Although health education has enhanced household knowledge of hygiene and disease linkage, inability to regularly wash hands with soap, inability for rural communities to finance maintenance of such facilities and child excreta disposal practices serve as constraints to disease reduction efforts. This paper demonstrates that limited access to water and sanitation services and poor hygiene practices adversely affects rural livelihoods, with significant consequences on community development. Thus, community development becomes problematic when there is limited access to water and sanitation combined with poor hygiene behaviours. The integration of water and sanitation issues into rural livelihoods development interventions aimed at enhancing community development is therefore recommended.

\section{References}

Adams, E.A., Boateng, G.O., and Amoyaw, J.A. (2016). Socioeconomic and demographic predictors of potable water and sanitation access in Ghana. Social Indicators Research, 126(2), pp. 673-687. 
Bartlett, S. (2003). Water, sanitation and urban children: the need to go beyond “improved" provision. Environment and Urbanization, 15(2), pp. 57-70.

Checkley, W., Gilman, R.H., Black, R.E., Epstein, L.D., Cabrera, L., Sterling, C.R., and Moulton, L.H. (2004). Effect of water and sanitation on childhood health in a poor Peruvian peri-urban community. The Lancet, 363(9403), pp. 112-118.

Cheng, J.J., Schuster-Wallace, C.J., Watt, S., Newbold, B.K., and Mente, A. (2012). An ecological quantification of the relationships between water, sanitation and infant, child, and maternal mortality. Environmental Health, 11(1), pp. 1-8.

Clarke, M., Feeny, S., and Donnelly, J. (2014). Water, sanitation and hygiene interventions in the Pacific: Defining, assessing and improving 'sustainability'. The European Journal of Development Research, 26(5), pp. 692-706.

Cooley, H., Ajami, N., Ha, M.L., Srinivasan, V., Morrison, J., Donnelly, K., and ChristianSmith, J. (2014). Global Water Governance in the Twenty-First Century. In P.H. Gleick (Ed.), The World's Water Volume 8: The Biennial Report on Freshwater Resources (pp. 1-18). Washington DC.: Springer.

Curry, E. (2010). Water scarcity and the recognition of the human right to safe freshwater. Northwestern Journal of International Human Rights., 9(1), pp. 103121.

Curtis, V., Cairncross, S., and Yonli, R. (2000). Review: Domestic hygiene and diarrhoea-pinpointing the problem. Tropical Medicine and International Health, 5(1), pp. 22-32.

CWSA. (2011). L.I. 2007 Community Water and Sanitation Agency Regulation, 2011. Accra, Ghana: Parliament of Ghana.

CWSA. (2014). National Community Water and Sanitation Programme, Project Implementation Manual. Accra: Ministry of Wate Resources, Work and Housing.

Dangour, A. D., Watson, L., Cumming, O., Boisson, S., Che, Y., Velleman, Y., . . Uauy, R. (2013). Interventions to improve water quality and supply, sanitation and hygiene practices, and their effects on the nutritional status of children. Cochrane database system review, 8(9).

Doe, S. R., and Khan, M. S. (2004). The boundaries and limits of community management: Lessons from the water sector in Ghana. Community Development Journal, 39(4), pp. 360-37.

Ejemot, R., Ehiri, J., Meremikwu, M., and Critchley, J. (2008). Hand washing for preventing diarrhoea. Cochrane database syst review, 1(4), pp. 893-939.

Fewtrell, L., Prüss-Üstün, A., Bos, R., Gore, F., and Bartram, J. (2007). Water, sanitation and hygiene: Water, sanitation and hygiene: quantifying the health impact at 
national and local levels in countries with incomplete water supply and sanitation coverage. Geneva: World Health Organization Retrieved from https://apps.who. int/iris/bitstream/handle/10665/43763/9789241595759_eng.pdf;j Accessed: 15th January 2019.

Freeman, M.C., Greene, LE., Dreibelbis, R., Saboori, S., Muga, R., Brumback, B., and Rheingans, R. (2012). Assessing the impact of a school-based water treatment, hygiene and sanitation programme on pupil absence in Nyanza Province, Kenya: a cluster-randomised trial. Tropical Medicine and International Health, 17(3), pp. 380-391.

Ghana Health Service. (2012). Annual Progress Report. Accra: Ghana Health Services.

Ghana Statistical Service. (2018). Ghana Living Standard Survey Round 7 (GLSS 7). Poverty Profile in Ghana (2016-2017). Accra: Ghana Statistical Service.

Gilchrist, A., and Taylor, M. (2016). The Short Guide to Community Development $2 e$. University of Bristol, United Kingdom: Policy Press.

Giné, R., and Pérez-Foguet, A. (2008). Sustainability assessment of national rural water supply program in Tanzania. Natural Resources Forum, 32(4), pp. 327-342.

Gleick, P.H. (2002). Dirty-water: Estimated Deaths from Water-related Diseases 20002020: Pacific Institute for Studies in Development, Environment, and Security.

Graf, J., Meierhofer, R., Wegelin, M., and Mosler, H.J. (2008). Water disinfection and hygiene behaviour in an urban slum in Kenya: impact on childhood diarrhoea and influence of beliefs. International Journal of Environmental Health Research, 18(5), pp. 335-355.

Hanjra, M.A., and Qureshi, M.E. (2010). Global water crisis and future food security in an era of climate change. Food Policy, 35(5), pp. 365-377.

Hutton, G., Haller, L., and Bartram, J. (2007a). Economic and health effects of increasing coverage of low cost household drinking-water supply and sanitation interventions to countries off-track to meet MDG target 10 Economic and health effects of increasing coverage of low cost household drinking-water supply and sanitation interventions to countries off-track to meet MDG target 10. Geneva, Switzerland: WHO. https://d26p6gtom19hor.cloudfront.net/ whywater/mdg10_offtrack.pdf. Accessed: 10th December 2018.

Hutton, G., Haller, L., and Bartram, J. (2007b). Global cost-benefit analysis of water supply and sanitation interventions. Journal of Water and Health, 5(4), pp. 481502. 
Jasper, C., Le, T.T., and Bartram, J. (2012). Water and sanitation in schools: a systematic review of the health and educational outcomes. International Journal of Environmental Research and Public Health, 9(8), pp. 2772-2787.

Kendie, B. (2002). Linking water supply, sanitation and hygiene in Northern Ghana. Cape Coast, Ghana: Catholic Mission Press.

Mohamed, H., Clasen, T., Njee, R.M., Malebo, H.M., Mbuligwe, S., and Brown, J. (2016). Microbiological effectiveness of household water treatment technologies under field use conditions in rural Tanzania. Tropical Medicine and International Health, 21(1), pp. 33-40.

Montgomery, M.A., and Elimelech, M. (2007). Water and sanitation in developing countries: including health in the equation. Environmental Science and Technology, 41(1), pp. 17-24.

Opryszko, M.C., Guo, Y., MacDonald, L., MacDonald, L., Kiihl, S., and Schwab, K.J. (2013). Impact of water-vending kiosks and hygiene education on household drinking water quality in rural Ghana. The American Journal of Tropical Medicine and Hygiene, 88(4), pp. 651-66o.

Pinstrup-Andersen, P. (2009). Food security: definition and measurement. Food security, 1(1), pp. 5-7.

Rufener, S., Mäusezahl, D., Mosler, H.J., and Weingartner, R. (2010). Quality of drinking-water at source and point-of-consumption-drinking cup as a high potential recontamination risk: a field study in Bolivia. Journal of Health, Population, and Nutrition, 28(1), pp. 34.

Saleth, R.M., and Dinar, A. (2004). The Institutional Economics of Water: A CrossCountry Analysis of Institutions and Performance. Cheltenham, UK Edward Elgar Publishing Limited.

Schouten, T., and Moriarty, P. (2003). Community Water, Community Management: From System to Service in Rural Areas. London: Practical Action Publishing.

Strina, A., Cairncross, S., Barreto, M., Larrea, C., and Prado, M. (2003). Childhood diarrhea and observed hygiene behavior in Salvador, Brazil. American Journal of Epidemiology, 157(11), pp. 1032-1038.

United Nations. (2003). People and the Planet, Facts and Figures about Water and Health. Paris, France: UNESCO.

Usman, M.A., Gerber, N., and von Braun, J. (2018). The Impact of Drinking Water Quality and Sanitation on Child Health: Evidence from Rural Ethiopia. The Journal of Development Studies, 55(10), pp. 1-19. 
Van Houweling, E., Hall, R.P., Sakho Diop, A., Davis, J., and Seiss, M. (2012). The role of productive water use in women's livelihoods: Evidence from rural Senegal. Water Alternatives, 5(3), pp. 658-677.

Van Koppen, B., Moriarty, P., and Boelee, E. (2006). Multiple-use water services to advance the millennium development goals. IWMI: https://www.ircwash.org/ sites/default/files/Koppen-2006-Multiple.pdf. Accessed: 18th January 2019.

WHO. (1992). Water, A Hope for Africa-Eradication of Guinea Worm. Geneva, Switzerland: World Health Organisation.

WHO. (2002). Health Dimensions, Economic Reform. Geneva, Switzerland: World Health Organisation.

WHO/UNICEF. (2014). Progress on Drinking Water and Sanitation. Geneva: WHO Press.

Wright, J., Gundry, S., and Conroy, R. (2004). Household drinking water in developing countries: a systematic review of microbiological contamination between source and point-of-use. Tropical Medicine and International Health, 9(1), pp. 106-117.

Zhang, J. (2012). The impact of water quality on health: Evidence from the drinking water infrastructure program in rural China. Journal of Health Economics, 31(1), pp. 122-134. 